\title{
Long-term treatment with high-dose of sildenafil in a thalassemic patient with pulmonary hypertension
}

\author{
Terapia a lungo termine con alte dosi di sildenafil \\ in un paziente talassemico con ipertensione polmonare
}

\author{
Michele Correale1, Fiorella De Rosa1, Riccardo leva1, \\ Matteo Di Biase2 ${ }^{2}$, Natale Daniele Brunetti3
}

\begin{abstract}
Long-term treatment with high-dose of sildenafil in a thalassemic patient with pulmonary hypertension. M. Correale, F. De Rosa, R. Ieva, M. Di Biase, N.D. Brunetti.

We report a case of a 37-years-old man, affected by thalassemia major, hypogonadotropic hypogonadism, chronic HCV-hepatitis, diabetes mellitus, severe osteoporosis, prior septic pulmonary embolism and pulmonary artery hyper-
\end{abstract}

tension was performed a long-term treatment with highdose of sildenafil $(120 \mathrm{mg} / \mathrm{die})$ with reduction of pulmonary arterial systolic pressure and of the dyspnea.

Keywords: pulmonary arterial hypertension; thalassemia major, sildenafil.

Monaldi Arch Chest Dis 2012; 78: 105-106.

\footnotetext{
1 University of Foggia, Department of Cardiology.

2 Professor, University of Foggia, Department of Cardiology.

3 Assist Professor, University of Foggia, Department of Cardiology.
}

Corresponding author: Michele Correale, MD; Department of Cardiology, "Ospedali Riuniti" OO.RR.; Viale L. Pinto, 1; 71100 Foggia, Italy; E-mail address: opsfco@tin.it; Tel.+390881733652; Fax +390881745424

\section{Case}

A 37-years-old man, affected by thalassemia major, hypogonadotropic hypogonadism, chronic HCV-hepatitis, diabetes mellitus and severe osteoporosis, was admitted in 2007 to our Department for endocarditis associated to septic pulmonary embolism. An anticoagulant therapy was immediately started. In 2009, an echocardiographic examination performed for dyspnea, showed dilated right chambers and left ventricle with D-shaped configuration (Fig. 1). The continuous-wave Doppler showed a systolic gradient of $82 \mathrm{mmHg}$. Having refused to undergo cardiac catheterization a therapy for pulmonary arterial hypertension (PAH) was started (e.g. digitalis, diuretics and anticoagulants), but after six months patient experienced heart failure with increasing dyspnea (NYHA III-IV class). Having still refused to undergo cardiac catheterization the patient started a treatment with phosphodiesterase inhibitors (sildenafil $40 \mathrm{mg} /$ day), with early symptomatic improvement (e.g. decrease of dyspnea and improved NYHA functional class II-III) and decrease of pulmonary arterial systolic pressure to $44 \mathrm{mmHg}$, measured at the subsequent echocardiographic examination (July 2010). On November 2010 he was urgently admitted to the department of Internal Medicine with dyspnea (NYHA class III-IV) and worsening of pulmonary arterial systolic pressure $(70 \mathrm{mmHg})$; therefore a titration therapy with sildenafil was started. It was decided not to use endothelin receptor antagonists because of a concomitant chronic HCV-hepatitis. The progressive increase of sildenafil dosages determined a decrease of dyspnea and improvement of NYHA functional class. In February 2011, the continuous-wave Doppler showed a peak velocity consistent with a pressure

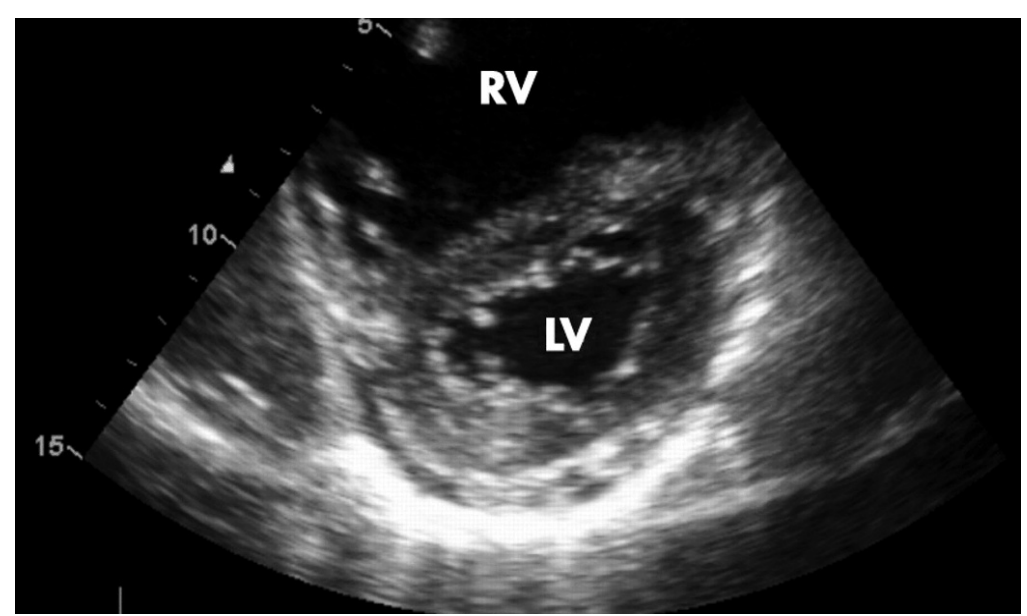

Figure 1. - Two-dimensional echocardiogram: apical four-chamber view of the heart revealing right chambers dilatation. 
gradient of $50 \mathrm{mmHg}$ and a pulmonary arterial systolic pressure of $60 \mathrm{mmHg}$. In June 2011, the patient was under treatment with sildenafil $120 \mathrm{mg} /$ day and in NYHA functional class II.

\section{Discussion}

PAH is a frequently observed condition in patients with thalassemia $(10 \%$ in thalassemia major and more than $50 \%$ in thalassemia intermedia) [1].

Thalassemia major is an inherited haemoglobin disorder characterized by severe hemolytic anemia, requiring transfusional therapy for survival. The etiology of PAH in thalassemic patients remains unclear. Obstruction of pulmonary arteries by thrombotic events has been observed in patients with thalassemia/HbE disease [3]. In our case, the patient had a previous history of pulmonary embolism as well.

Erythroblasts and damaged erythrocytes, loosing their normal symmetric distribution of membrane phospholipids, seem to have a pro-coagulant activity. The low hemoglobin levels, especially in untransfused patients, lead to compensatory hyperplasia of erythroblasts and to an increase of their circulating levels, thus increasing the thrombotic risk.

In addition, chronic anaemia induces a decrease of peripheral resistances with a consequent increase of venous return and cardiac output. The consequences are represented by an enlargement and a decrease of cardiac cavities contractility, with involvement of both ventricles, in some cases with prevalent left ventricular and in others with prevalent right ventricular involvement [1]. Haemolysis, another typical feature of thalassemia, eliminates nitric oxide and releases arginase which breaks down arginine, the substrate for nitric oxide formation [1].

In the case here reported, the patient showed a prevalent right ventricular involvement and pulmonary hypertension. Because of the worsening of pulmonary systolic pressure, he started titration therapy with sildenafil. Endothelin receptor antagonists were not used because of a concomitant chronic HCV-hepatitis. The titration of sildenafil, up to the dosage of $120 \mathrm{mg} / \mathrm{die}$, led to the decrease of dyspnea and improvement of NYHA class (II). Our results confirm previous reports.

Indeed, Littera et al showed a 34-year-old male with thalassemia intermedia and secondary PHT, with a history of splenectomy (18 years) and regular blood transfusion and iron chelation therapy (32 years), who had been successfully treated with sildenafil [3]. In this case, echocardiography showed a steady increase of pulmonary arterial pressure (PAP), right ventricular enlargement, moderate tricuspid valve regurgitation (systolic Tricuspid Gradient [TG] $56 \mathrm{mmHg}$, mean $42 \mathrm{mmHg}$ ), and a left ventricular systolic function preserved. Calcium antagonists were the initial treatment, but they had to be withdrawn early due to severe side effects. Afterwards, sildenafil was administered at 25 $\mathrm{mg}$ b.i.d. for one month and the dose was progressively increased to $50 \mathrm{mg}$ b.i.d. After 15 months of therapy, right ventricular size and the mean TG were within the normal values (systolic TG 40 $\mathrm{mmHg}$, mean $25 \mathrm{mmHg}$ ).
Furthermore, Derchi et al evaluated the efficacy of sildenafil treatment in patients with hemoglobinopathies (thalassemia intermedia $n=4$; thalassemia major $n=2$; sickle thalassemia $n=1$ ) and severe PAH. These patients were treated with sildenafil citrate (50 $\mathrm{mg}$ b.i.d.), for periods ranging from 4 to 48 months [4]. A significant decrease in pulmonary arterial pressure and improvement in exercise capacity and functional class were observed. No significant adverse events were reported.

In conclusion, thalassemic patients should be treated with therapeutic strategies aimed at reducing the pulmonary arterial pressure, combined with adequate transfusional support and iron chelation therapy to reduce hypoxic effect on the pulmonary vessels [1]. Specific drugs suitable for pulmonary arterial hypertension are available: calcium channel blockers, effective in only $30 \%$ of patients and difficult to manage in hypotensive thalassemic patients; endothelin-1 receptor antagonists, which can exacerbate elevated hepatic enzyme levels in patients with thalassemia and liver disorders; prostacyclin analogs, difficult to administer (e.g. subcutaneous or by continuous infusion) and very expensive. In summary, because of the selective antihypertensive effect, the minimal risk of side effects, and the possibility of oral administration, sildenafil appears to be a selective and powerful inhibitor of cGMP specific phosphodiesterase (PDE5), thus promoting smooth muscle relaxation in lung vascular vessel, and being an attractive alternative to conventional therapy for PAH in thalassemic patients.

\section{Riassunto}

Riportiamo il caso di un uomo di 37 anni, affetto da thalassemia major, ipogonadismo ipogonadotropico, epatopatia HCV correlata, diabete mellito, severa osteoporosi, pregresso episodio di embolia polmonare ed ipertensione arteriosa polmonare, che è stato sottoposto a terapia per lungo tempo con alti dosaggi di sildenafil (120 mg/die) con riduzione della pressione arteriosa polmonare e miglioramento della dispnea.

\section{References}

1. Cogliandro T, Derchi G, Mancuso L et al. Guideline recommendations for heart complications in thalassemia major. J Cardiovasc Med (Hagerstown). 2008; 9(5): 515-525.

2. The Task Force for the Diagnosis and Treatment of Pulmonary Hypertension of the European Society of Cardiology (ESC) and the European Respiratory Society (ERS), endorsed by the International Society of Heart and Lung Transplantation (ISHLT). Guidelines for the diagnosis and treatment of pulmonary hypertension. European Heart Journal 2009; 30: 2493-2537.

3. Littera R, La Nasa G, Derchi G et al. Long-term treatment with oral sildenafil in a thalassemic patient with pulmonary hypertension. Blood 2002; 100: 1516-1517.

4. Derchi G, Forni GL, Formisano F et al. Efficacy and safety of sildenafil in the treatment of severe pulmonary hypertension in patients with hemoglobinopathies. Haematologica 2005; 90: 452-458. 